This article was downloaded by: [Levinson, David]

On: 26 July 2010

Access details: Access Details: [subscription number 924778850]

Publisher Taylor \& Francis

Informa Ltd Registered in England and Wales Registered Number: 1072954 Registered office: Mortimer House, 3741 Mortimer Street, London W1T 3JH, UK

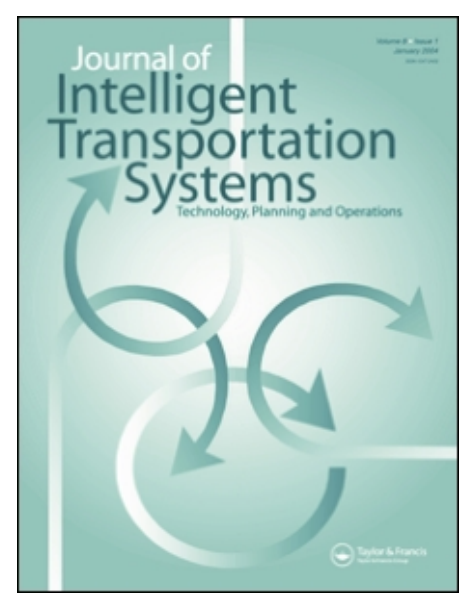

\title{
Journal of Intelligent Transportation Systems
}

Publication details, including instructions for authors and subscription information:

http://www.informaworld.com/smpp/title $\sim$ content=t713398522

\section{A Moment of Time: Reliability in Route Choice Using Stated Preference}

Nebiyou Y. Tilahun ${ }^{\mathrm{a}}$; David M. Levinson

${ }^{a}$ Urban Transportation Center, University of Illinois at Chicago, ${ }^{b}$ Department of Civil Engineering,

University of Minnesota, Minneapolis

Online publication date: 26 July 2010

To cite this Article Tilahun, Nebiyou Y. and Levinson, David M.(2010) 'A Moment of Time: Reliability in Route Choice Using Stated Preference', Journal of Intelligent Transportation Systems, 14: 3, $179-187$

To link to this Article: DOI: 10.1080/15472450.2010.484751

URL: http://dx.doi.org/10.1080/15472450.2010.484751

\section{PLEASE SCROLL DOWN FOR ARTICLE}

Full terms and conditions of use: http://www.informaworld.com/terms-and-conditions-of-access.pdf

This article may be used for research, teaching and private study purposes. Any substantial or systematic reproduction, re-distribution, re-selling, loan or sub-licensing, systematic supply or distribution in any form to anyone is expressly forbidden.

The publisher does not give any warranty express or implied or make any representation that the contents will be complete or accurate or up to date. The accuracy of any instructions, formulae and drug doses should be independently verified with primary sources. The publisher shall not be liable for any loss, actions, claims, proceedings, demand or costs or damages whatsoever or howsoever caused arising directly or indirectly in connection with or arising out of the use of this material. 


\title{
A Moment of Time: Reliability in Route Choice Using Stated Preference
}

\author{
NEBIYOU Y. TILAHUN ${ }^{1}$ and DAVID M. LEVINSON ${ }^{2}$ \\ ${ }^{1}$ Urban Transportation Center, University of Illinois at Chicago \\ ${ }^{2}$ Department of Civil Engineering, University of Minnesota, Minneapolis
}

\begin{abstract}
Understanding how reliability is valued is important because it provides insight into how aims of policies that aspire to provide better transport options can be more fully integrated with user expectations. Better reliability is a desired outcome of transportation policies because it reduces scheduling costs. This study uses a stated preference survey to collect route preference data, in which each route is described by the travel time experience on it. Because travel-time decisions are made from momentary recollections of past experience, the paradigm adopted in this study is that the mode travel time rather than the mean is the important basis for travel time decisions. The authors then explore three alternate measures of reliability and use them to estimate route choice models on the basis of the stated preference data. Two of the measures, range coupled with lateness probability and standard deviation, have been explored before. A third measure based on time moment (moments of inertia) measured from the mode travel time is also proposed and tested. Each measure reveals something different about how people value different aspects of reliability. In all cases, reliability is valued highly, although differently depending on how it is defined. The values of reliability and travel time highlight that transportation policy makers can provide significant benefits to users from strategies that seek to increase reliability.
\end{abstract}

Keywords travel-time reliability; reliability ratio; value of reliability; unexpected delay; unexpected early; mode travel time

\section{INTRODUCTION}

Traditional analysis of transportation projects considers travel time as the primary cost to the user. As such, travel time savings often comprise the bulk of the benefits derived from many transportation projects. More recently, however, other aspects of travel such as the reliability have been getting more attention as can be seen by the increasing number of studies coming out in this area. Some of these studies have distinguished between different types of reliability issues that transportation networks face; namely, connectivity reliability, travel-time reliability, and capacity reliability (Nicholson, Schmöcker, and Bell, 2003; Yang, Lo, and Tang, 2000). Of these, we focus on travel-time reliability. Incorporating reliability in the analysis framework not only improves our models of choice and makes

Address correspondence to Nebiyou Y. Tilahun, Urban Transportation Center, University of Illinois at Chicago, 412 S. Peoria Street, Chicago, IL 60607. E-mail: ntilahun@uic.edu them more realistic, but also informs areas that are important in addressing travelers' needs for reliable travel times. These may include both implementations of intelligent transportation systems solutions such as advanced traveler information systems that allow information to reach travelers en-route (Schmöcker and Lo, 2009), as well as policy decisions that involve pricing and other strategies to manage demand.

The concept of travel-time reliability is one that is related to the variability in experienced travel time. From a user's perspective, increased variability makes scheduling difficult by creating the possibilities of early or late arrival and introduces risk in the decision-making process. In the route-choice context, one can think of the choice dilemma as a gamble between travel-time outcomes on alternate routes. It is unlikely, for example, that a person would opt for a route that has a 50-50 chance of being 10 min early or 10 min late if there is an alternative that offers the same expected travel time with certainty. This is especially true on repeated, constrained trips such as the morning work commute. What this implies from an expected utility perspective is 
that, for the risk-averse traveler, ignoring the risk introduced by the variability of travel time would underestimate the disutility of using the variable route.

Gaver (1968) introduced the importance of variability in travel decision making. His work focused on how travelers combat lateness due to variability of travel time by leaving earlier than they would have in the absence of variability. He proposed different head-start strategies, taking into consideration delay distributions and costs of both lateness and excessive head starts. A later study by Small (1982) empirically estimated a model for scheduling work trips. Small's formulation explicitly considered the costs associated with early and late arrival in addition to the travel-time cost and a fixed cost for arriving late. His results showed that individuals are more averse to being late than being early, but that being early was also associated with a disutility. Small's work highlighted the importance of predictability of trip times and confirmed that there is a value for being able to precisely predict how long a trip would take.

One can then think of travel-time reliability as the stability of trip times on a particular trip type faced by a traveler (Brownstone and Small, 2005). On a reliable route, the travel time encountered deviates very little from what is expected. If one assumes that participants make route decisions on the basis of his or her previous experience on the routes available, his or her most reliable choice would be the one that has provided him or her a stable service over time.

To capture the nature of choice and the tradeoffs in travel time and its variability, researchers have used several utility forms. One application in the risk literature is the mean-variance model, which can be derived by assuming a quadratic utility function in expected travel time. A variant of this model that has been used in the transportation literature is the mean-standard deviation utility formulation. Both of these approaches attempt to capture individual responses to risk by trading off the spread of the travel time distribution with the expected travel time and are sometimes used with additional variables. For example, a study by Jackson and Jucker (1982) tried to explicitly address this tradeoff between travel time and its variability by using a questionnaire that presented paired route choices to respondents. The choices specified a route that has a higher usual travel time and no possible delays, and another that had a lower usual time but with a possible delay that is of varying magnitudes encountered once per week. Their analysis finds that travel time variability has an important effect on the chosen route to work; however, they also find significant variability between the participants in how they responded to this variability.

Black and Towriss's (1993) study also looked at the mean travel time and standard deviation tradeoff. They estimated a generalized cost function from stated preference data that has mean travel time, its standard deviation and travel cost as its components for various trip activities, different modes, different durations, and so forth, to explore effects of travel time variability on demand. They find that reliability (as measured by the standard deviation of travel time) is an important component of the cost function; however, the magnitude of their estimated coefficient for the standard deviation is smaller than that for the mean travel time.

Black and Towriss (1993) also defined a reliability ratio as the ratio of the value of reliability to that of the value of time in the cost (utility) function and found a value of 0.70 for the entire data set (e.g., all modes, all trips) and a value of 0.55 for trips to/from work by car. Subsequently, other researchers have also calculated this value. For example, Noland and Small (1998) found a reliability ratio of 1.27 , whereas Small, Noland, $\mathrm{Chu}$, and Lewis (1999) found a value of 3.22. A review of these studies and others that have focused on travel-time reliability is provided in Noland and Polak (2002).

Formulations that solely depend on the standard deviation to account for the variability in travel time can lose important information about individual preferences. The standard deviation cannot distinguish between preferences for being early and late. The mean-standard deviation formulation is also not sufficient to characterize distributions fully unless they resemble a normal distribution. The mean-variance and mean-standard deviation models and circumstances in which they can be inconsistent are discussed in de Palma and Picard (2006). Another variable that has been used to describe the significant departures from usually experienced travel time is the range of the travel time distribution. Brownstone and Small (2005), for example, used the difference between the 90th and 50th percentile travel times. This can also be coupled with probability measures of being late to include more information about the distribution in question.

For the decision maker, however, such detailed information on the distribution of travel time is not available. Since individuals make decisions based on recalled experience, it is likely that their decision making is based on much simpler heuristic rules that condense the detailed information in the actual distribution. In the following sections, we discuss a stated preference survey that was prepared and administered to extract the value of reliability. That will be followed by a discussion of alternate utility specifications that could be used and what each may tell us about the nature of peoples choice. We then present a model estimated on the stated preference data, then discuss the models.

\section{SURVEY}

This study used a computer-administered stated-preference survey. The stated-preference approach allows us to test a variety of travel time and cost combinations that in reality are difficult to acquire for each individual. It gives us more control over the variables of interest and overcomes many of the consistency problems that arise in revealed preference data. Statedchoice methods are discussed in detail in Louviere, Hensher, and Swait's (2000) article. It has also been used in evaluating traveler response to intelligent transportation systems solutions such as using traveler information systems (Khattak, Koppelman, and Schofer, 1993; Khattak, Polydoropoulou, and Ben-Akiva, 1996). 


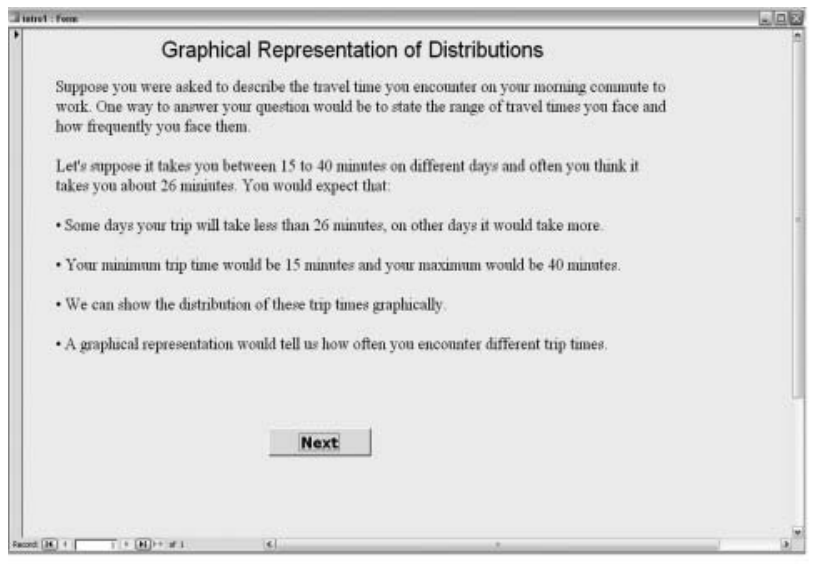

Side 1

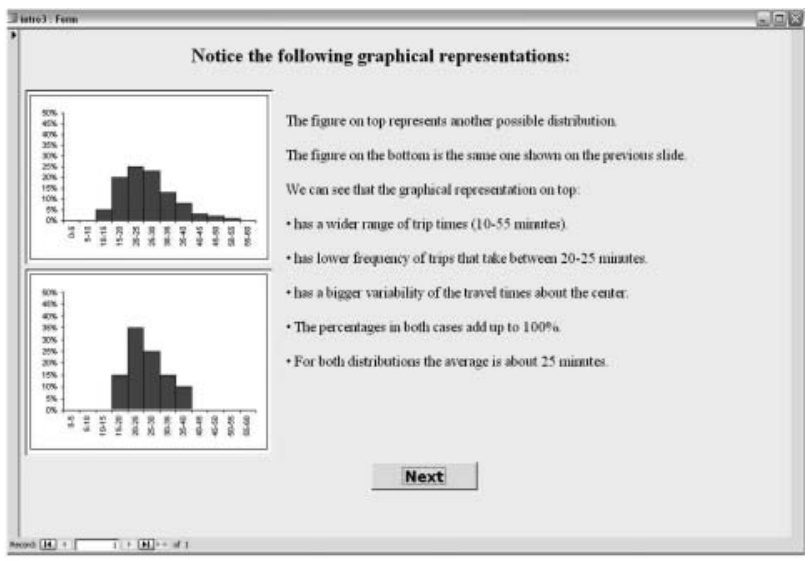

Slide 3

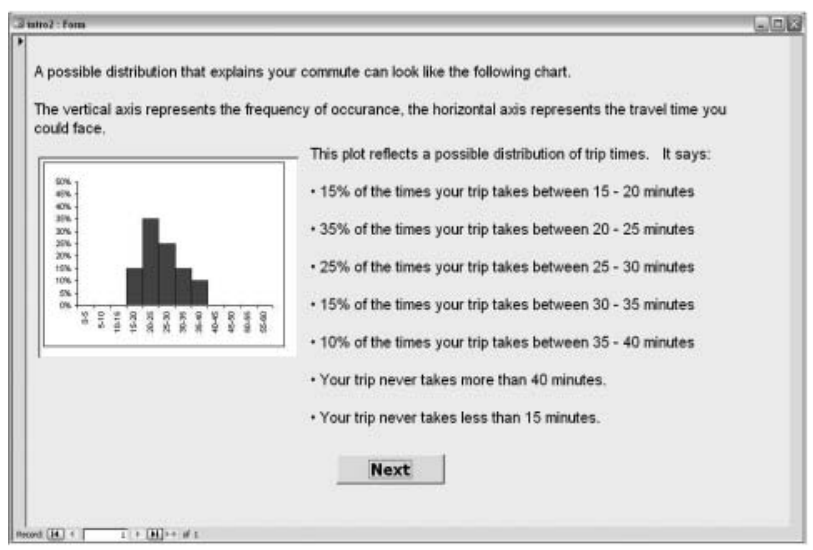

Slide 2

Figure 1 Tutorial presentations.

The use of stated preference comes with some challenges such as unreasonable choices being made because there are no real consequences to the choice or because participants misunderstand the question. We took two measures to hedge against these problems. The first was giving tutorials to the participants about the information presented in the questionnaires including how to interpret distributions. The tutorials used examples that were similar in form to the ones in the actual questionnaire. The tutorial covered interpreting frequencies, mean, and variance, as well as how to compare different distributions. Figure 1 presents screen shots of the tutorials.

In addition to the tutorials, the questionnaires included two control questions randomly placed among the actual route choice questions. These were placed as a test of both whether the individuals understood the questions, as well as to see whether they were paying attention to the questions and answering them in a reasonable fashion. The control questions had clearly dominated choice alternatives where the person who misunderstood the question could choose to pay more to use a clearly less reliable and higher travel-time route.

After the tutorial, participants were presented with 15 routechoice questions in random order. Two of these were the aforementioned control questions. The remaining were based on 26 routes with different travel-time distributions and toll combinations. The alternatives were matched with one another such that the correlation between key variables was minimal. None of the choice sets was dominated. The differences between the mode travel time ranged from 0 to $15 \mathrm{~min}$, the difference in standard deviation ranged from -1.3 to -3.9 min, differences in left range from the mode ranged from 0 to $-10 \mathrm{~min}$, differences in the right range ranged from -5 to $-15 \mathrm{~min}$, and differences in the toll ranged from $\$ 0$ to $\$ 2.50$. The maximum correlation between variables used together in the choice model was between the travel time and toll variables, which equaled 0.31 . Sample presentations of the survey are given in Figure 1. There were a total of six randomizations on the order of the questions. Participants were randomly assigned to one of the randomized sets.

Participants for the survey were recruited via e-mail from the University of Minnesota's employee database. Invitations were sent out to 2,500 randomly selected nonfaculty, nonstudent employees who had not participated in previous transportation studies conducted by the authors. The recruitment e-mail indicated that individuals were invited to participate in a computer 
Table 1 Summary of participant statistics.

\begin{tabular}{lrr}
\hline Number of subjects & 177 & \\
\hline Sex & & \\
$\quad$ Male & 94 & $53.1 \%$ \\
$\quad$ Female & 83 & $46.9 \%$ \\
Age Mean (Std. deviation) & & $40.3(11.8)$ \\
Usual commute mode (Year round) & & \\
$\quad$ Car & 131 & $74.0 \%$ \\
$\quad$ Transit & 31 & $17.5 \%$ \\
Bike & 10 & $5.6 \%$ \\
Walk & 5 & $2.8 \%$ \\
Education & & \\
College Level & 144 & $81.4 \%$ \\
Less than college level & 33 & $18.6 \%$ \\
Household income & & \\
$\quad<30,000$ & 32 & $18.1 \%$ \\
\$30,000-\$45,000 & 81 & $45.8 \%$ \\
\$45,000-\$60,000 & 43 & $24.3 \%$ \\
\$60,000-\$75,000 & 15 & $8.5 \%$ \\
$\quad$ \$75,000-\$100,000 & 6 & $3.4 \%$ \\
$>\$ 100,000$ & 0 & $0.0 \%$ \\
Commute Time & & \\
$<15$ Minutes & 22 & $12.4 \%$ \\
$15-29$ Minutes & 94 & $53.1 \%$ \\
$30-44$ Minutes & 44 & $24.9 \%$ \\
$45-59$ Minutes & 9 & $5.1 \%$ \\
$>1$ Hour & 8 & $4.5 \%$ \\
\hline & & \\
\hline & &
\end{tabular}

based commute study and offered $\$ 15$ for participation. Participants were asked to come to a central testing station, where the survey was administered. On the basis of previous experience of similar recruitments, a target of 200 participants was set. A total of 187 respondents agreed and participated in the study. Of these, 10 were dropped from the analysis; 8 had made irrational choices on the control questions, and the other 2 failed to provide demographic information that were necessary in the model fitting. Table 1 shows descriptive statistics of the 177 participants used in this study.

\section{ANALYSIS}

The work commute route choice is a recurring problem for the traveler. There are many ways in which individuals could choose their route, but, in general, the decisions are assumed to revolve around cost. These include direct monetary and time costs as well as costs induced by possibilities of late or early arrival. In the absence of additional information about how particular routes are performing at the time of travel, it can be fairly assumed that individuals would make decisions based on recalled experience.

We argue that these choices are more likely to be based on their usual or most frequent travel time and on any notable departures from what they consider usual rather than on the mean and the standard deviation which are not directly experienced by the traveler. Minor deviations in travel time may in fact be ignored in this decision-making process. It is more often that we hear people talking about a trip taking them 15 or 20 min rather than 16 or $19 \mathrm{~min}$. This observation is not just anecdotal. Of the 187 people who participated in this present study, 166 (88\%) of them reported their travel times in multiples of 5 min when asked to fill it in. Such thinking can easily cluster travel times that are close together into one lump, making the perceived usual experience highly pronounced and the basis for a route decision. Lateness can also be perceived similarly in which individuals recall their experience as $5 \mathrm{~min}$ late once in a while, $10 \mathrm{~min}$ late rarely, and so forth, highlighting a likely distinction between how people make their choices and how these are modeled.

The analysis here therefore considers the experienced travel time rather than the more abstract expected travel time as the basis for decision making. This is done first from a perspective that individuals are likely to recall their frequent experiences more easily and base decisions upon them than they are able to do a more drawn out calculation of expected travel time, and second, in the context of the present survey, it is easier for the participant to pick out the most frequent experience than it is to pick out the average for each distribution.

As discussed earlier, how a traveler weighs reliability may take different forms. In this paper we look at three possible ways of specifying the utility function. One possibility is that individuals make route decisions relating to reliability based on possibilities of early and late arrival coupled with their usual experience. In this formulation, given their experience, individuals would use the mode to position their preference on a particular route and then consider how much earlier or how much later they can be from that frequent experience.

The second stage in such a decision framework (anticipated earliness or lateness) actually requires more calculation than the first to get valid estimates of how late or how early the individual can be by using a particular alternative. In practice an individual may use any number of heuristics to make the decision (Zhang, 2006); we assume here that the average late $(L)$ or average early ( $E$; in minutes) from the most frequent experience is a representative way of getting together the possible range and frequencies experienced. Figure 3 presents a schematic of this paradigm.

The two moments $\mathrm{E}$ and $\mathrm{L}$ are calculated as follows (see Figure 3):

$$
\begin{aligned}
& E=\frac{1}{P(t<T)} \sum_{i} p_{i} \delta_{i}\left(T-t_{i}\right) \text { Where } \delta_{i}=\left\{\begin{array}{ll}
1 & \text { if } T \geq t_{i} \\
0 & \text { if } T<t_{i}
\end{array}\right\} \\
& L=\frac{1}{P(t>T)} \sum_{i} p_{i} \delta_{i}\left(t_{i}-T\right) \text { Where } \delta_{i}=\left\{\begin{array}{ll}
1 & \text { if } T \leq t_{i} \\
0 & \text { if } T>t_{i}
\end{array}\right\}
\end{aligned}
$$

$T=$ the most frequently encountered travel time

$t_{i}=$ possibly encountered travel time slice

$p_{i}=$ probability that $\mathrm{t}_{i}$ is encountered. 


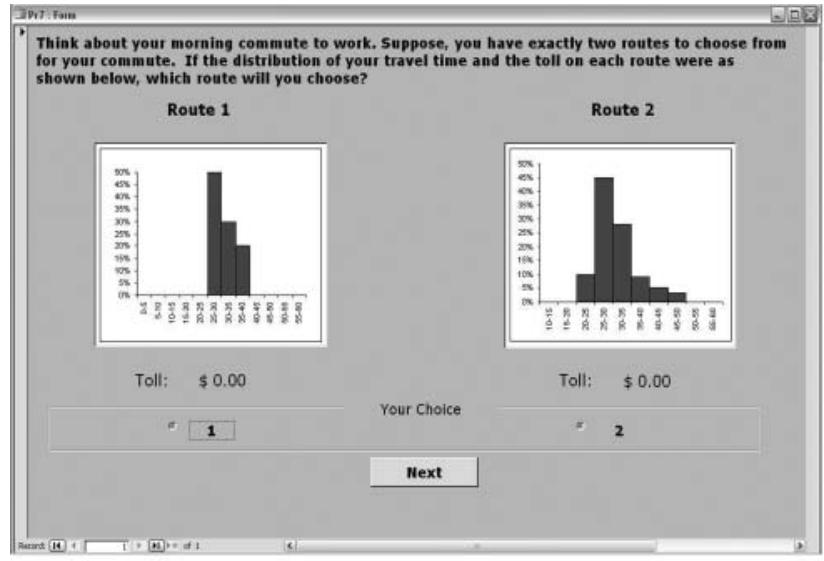

Sample 1

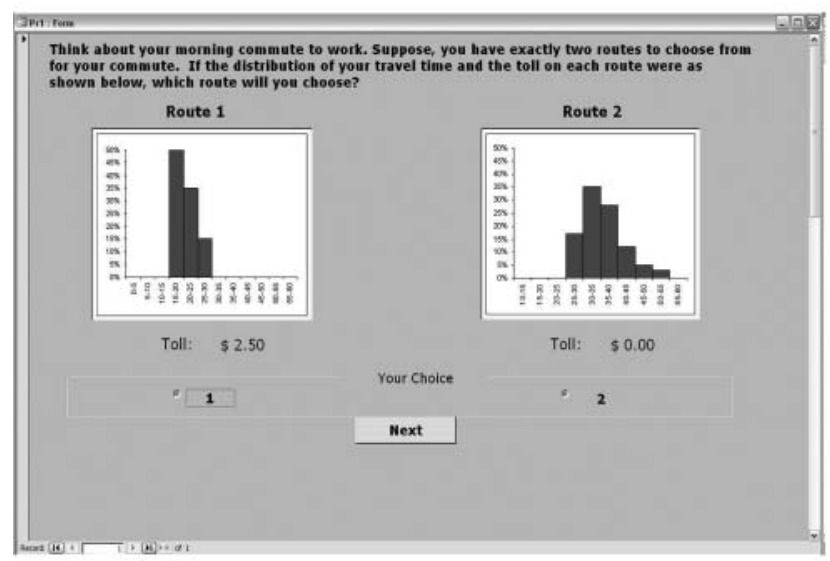

Sample 2

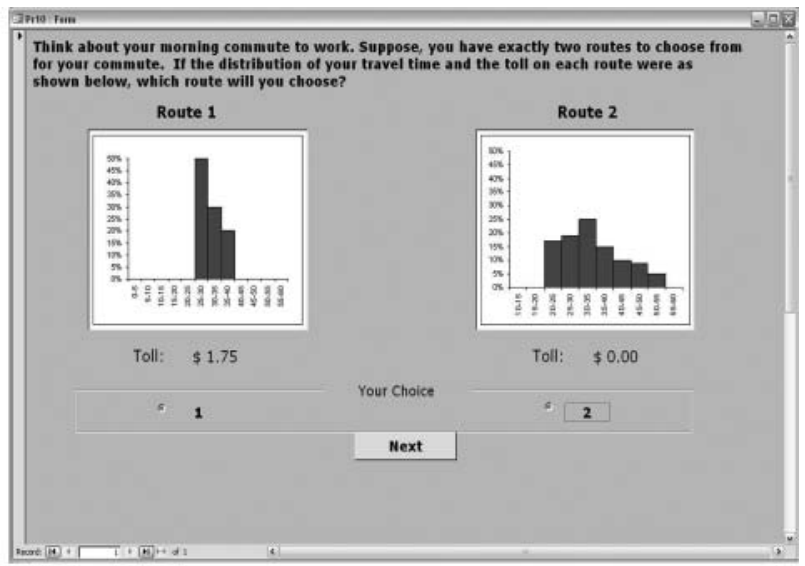

Sample 3

Figure 2 Sample screenshots of survey question.

$\mathrm{T}$.

$P(t>T)=$ The cumulative probability of arriving later than

$P(t<T)=$ The cumulative probability of arriving earlier than $\mathrm{T}$.

E: represents on average how early the traveler has been from their usual time by using that route.

$\mathrm{L}$ : represents on average how late that individual has been from their usual time by using that particular route.

A second possibility is that the decision may be motivated by extreme values of travel time in addition to the traveler's frequent experience. It is possible to capture this by using the range of travel time from the median to the extreme value (R in Figure 2). However, this approach overlooks how travel time is distributed from the median to the extreme value. One way to include this information is by measuring the aggregate lateness probability that this range encompasses. That approach is followed here, and we measure the aggregate probability that the individual is more than 5 min late from the mode travel time $(\mathrm{P})$ as a measure of the unreliability between routes.

A third possibility is that individuals would want to avoid overall variability of travel time. The standard deviation can be used in this case as a measure of overall unreliability. The weaknesses of this approach, including its inability to differentiate between preferences for earliness and lateness, have been discussed earlier. It can be used as basis for comparison with other studies.

We test these three alternate utility specifications, each differing from the other in how reliability is accounted for. Model 1 uses the moments paradigm previously illustrated (and

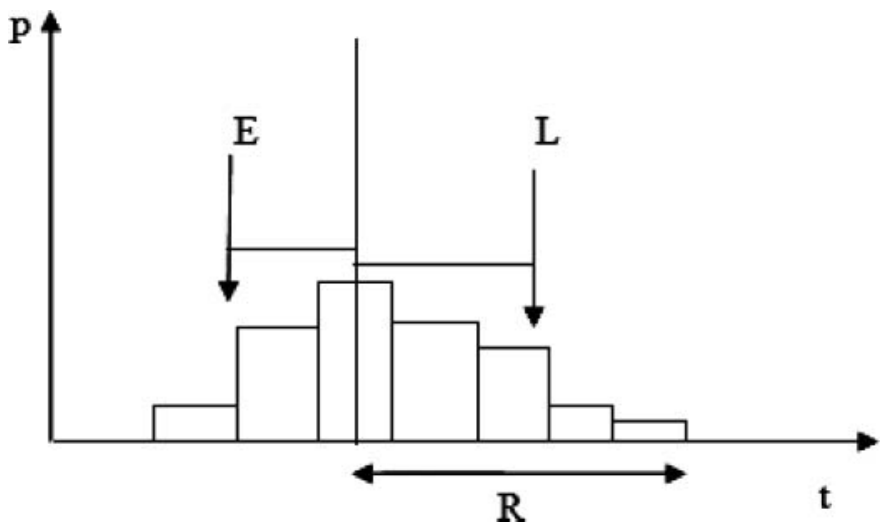

Figure 3 Decision schematic: Individual weighs the distribution from position of most frequent experience. $\mathrm{E}, \mathrm{L}=$ early and late expectations from mode; $\mathrm{R}=$ right range from the mode; $\mathrm{t}=$ travel time; $\mathrm{p}=$ probability of occurrence. 
Figure 3). Model 2 uses the right range as the measure of unreliability. Model 3 uses the standard deviation to measure unreliability. In addition to time, and the different measures of unreliability, we also expect out-of-pocket costs to affect the route choice decision. Generally, the higher the out-of-pocket cost, the less likely the route is liked by potential users all other things equal.

There may also be variations in preferences that relate to people's sociodemographic characteristics and individual tastes. Because the same individual appears repeatedly in the survey, we have included a random term to account for the participant to participant variation. A random parameter binomial logit model is estimated based on the collected data. The form of the model is as follows.

$$
\begin{aligned}
& \left(Y_{i j} / b_{i}\right) \sim \operatorname{binomial}\left(1, p_{i j}\right) \\
& \operatorname{logit}\left(p_{i j}\right)=U_{i j}+b_{i} \\
& b_{i} \sim N\left(0, \sigma^{2}\right) \\
& U_{i j}=V_{i j}+\varepsilon_{i j}
\end{aligned}
$$

The three functional utility forms that are estimated for individual $\mathrm{i}$ on alternative $\mathrm{j}$ are as follows:

$$
\begin{aligned}
& V_{i j}=\beta_{0}+\beta_{1} T_{i j}+\beta_{2} C_{i j}+\beta_{3} E_{i j}+\beta_{4} L_{i j} \quad \text { Model } 1 \\
& V_{i j}=\beta_{0}+\beta_{1} T_{i j}+\beta_{2} C_{i j}+\beta_{3} R_{i j}+\beta_{4} P_{i j} \quad \text { Model } 2 \\
& V_{i j}=\beta_{0}+\beta_{1} T_{i j}+\beta_{2} C_{i j}+\beta_{3} S_{i j} \quad \text { Model } 3
\end{aligned}
$$

where

$T=$ most frequent travel time on route $\mathrm{j}$ by individual $\mathrm{i}$

$C=$ toll cost of the trip

$L=$ on average, how late a traveler can be from $\mathrm{T}$

$E=$ on average, how early a traveler can be from $\mathrm{T}$

$\mathrm{R}=$ right range of the travel-time distribution (100-50th\%)

$\mathrm{P}=$ probability of being more than 5 min late from usual

$\mathrm{S}=$ standard deviation of travel time experienced

$b_{i}=$ random effect for person $i$

Other individual and sociodemographic variables are also used to track preference differences that may be important in the decision process. The following categorical variables were used to detect differences along socio demographic classes.

$A=$ age $(0=$ younger than 35 years, $1=35$ years and older $)$

$S=$ gender $(0=$ female, $1=$ male $)$

$I=$ personal income $(0=$ less than $\$ 60,000$ annually, $1=$

$\$ 60,000$ and more annually)

$M=$ usual mode $(1=$ car, $0=$ otherwise $)$

The age variable was initially divided up into three categories; however, no differences were found between the groups older than 35 years of age. The income variable had three groups initially ranging from $\$ 0$ to $30,000, \$ 30,000$ to
$\$ 60,000$, and $\$ 60,000$ and more. These were consolidated into two groups after we detected no differences between the first two groups in the model fitting. Table 2 shows the estimated model.

Each of these models confirms the importance of travel time, travel-time reliability, and cost in the respondent's choices. In each case, values of time and reliability are calculated and reported using marginal rates of substitution of time and reliability with the out-of-pocket cost. In each of the models, the coefficients for time and cost have stayed stable without being affected considerably. There is also a significant participant to participant heterogeneity as evidenced by the estimated variance of the random term.

According to Model 1, individuals are making a choice based on whether the mode travel time is small, whether the average lateness expected from a particular route is small, and how much toll is paid on a particular route. There is no evidence to suggest that the possibility of early arrival has any bearing on the decision to pick a particular route. This result is in contrast with studies that have shown a disutility associated with early arrival (Noland and Small, 1998; Small, 1982). It may be possible, however, that people are looking at the present context of the decision differently. If, for example, one imagines the route choice problem as being made once the decision maker is in their car, the alternative to arriving early would be to stay in the car driving. In making the decision about which route they prefer then, people may be concentrating on avoiding lateness primarily and they may not necessarily be paying attention to the possibilities of arriving early.

The value of time from Model 1 is estimated at $\$ 7.44 / \mathrm{hr}$ (CI $\$ 6.74 / \mathrm{hr}$ to $\$ 8.15 / \mathrm{hr}$ ), the value of reliability (VOR) is estimated at $\$ 7.11 / \mathrm{hr}$ (CI $\$ 4.43 / \mathrm{hr}$ to $\$ 9.79 / \mathrm{hr}$ ). The VOR is less precise than the VOT estimate. The marginal rate of substitution (MRS) between $\mathrm{L}$ and $\mathrm{T}$ is 0.96 (CI 0.56 to 1.34 ), which indicates that other things equal, for every 1-min increase in L, one could reduce $\mathrm{T}$ by $0.96 \mathrm{~min}$ and remain at the same utility. This is an important finding. It suggests that choices can be affected almost equally by unit changes in the average lateness from the usual travel time, as they are by unit changes in usual travel time.

The estimates from the second model also confirm that extreme travel times are not desirable. The time and cost coefficients have stayed close to that from Model 1, and the value of time is estimated at $\$ 8.07 / \mathrm{hr}$ (CI $(\$ 7.42 / \mathrm{hr}$ to $\$ 8.72 / \mathrm{hr}$ ). The value of reliability is much lower when the reliability is measured in this way. The value is $\$ 2.31 / \mathrm{hr}$ (CI $(\$ 0.81 / \mathrm{hr}$ to $\$ 3.80 / \mathrm{hr}$ ). Although a reduction in the range is desired, people are not willing to pay as much to reduce it as they are willing to pay to reduce the most frequent travel time. This is likely because extreme travel times though undesirable are already rare events and increasing the magnitude by small amounts does not carry as much weight as changing the magnitude of the often encountered travel times. Another variable measuring the early range (50th percentile minus lowest travel time) was not significant and was dropped from the model.
$\mathrm{T} 2$ 
Table 2 Stated preference models with participant-level random parameters.

\begin{tabular}{|c|c|c|c|c|c|c|c|c|c|}
\hline & \multicolumn{3}{|c|}{ Model 1} & \multicolumn{3}{|c|}{ Model 2} & \multicolumn{3}{|c|}{ Model 3} \\
\hline & Estimate & Std.Error & $\mathrm{p}$-val & Estimate & Std.Error & $\mathrm{p}$-val & Estimate & Std.Error & $\mathrm{p}$-val \\
\hline$\sigma^{2}($ Subject $)$ & 2.954 & 0.474 & 0.000 & 3.037 & 0.486 & 0.000 & 2.879 & 0.463 & 0.000 \\
\hline Constant & 1.902 & 0.427 & 0.000 & 1.413 & 0.494 & 0.005 & 1.835 & 0.427 & 0.000 \\
\hline $\mathrm{T}$ (Time) & -0.273 & 0.020 & 0.000 & -0.287 & 0.020 & 0.000 & -0.295 & 0.022 & 0.000 \\
\hline $\mathrm{C}(\mathrm{Cost})$ & -2.201 & 0.145 & 0.000 & -2.137 & 0.139 & 0.000 & -2.262 & 0.156 & 0.000 \\
\hline E (Early) & 0.015 & 0.029 & 0.615 & & & & & & \\
\hline L (Late) & -0.261 & 0.052 & 0.000 & & & & & & \\
\hline R (Right Range) & & & & -0.082 & 0.026 & 0.002 & & & \\
\hline P ( Prob > 5 min late $)$ & & & & -2.999 & 1.092 & 0.007 & & & \\
\hline S (Standard Deviation) & & & & & & & -0.261 & 0.085 & 0.002 \\
\hline A $(1=>35,0$ otherwise $)$ & -0.643 & 0.340 & 0.060 & -0.651 & 0.344 & 0.060 & -0.636 & 0.336 & 0.060 \\
\hline $\mathrm{G}($ Male=1, Female=0) & -0.557 & 0.294 & 0.060 & -0.565 & 0.297 & 0.059 & -0.551 & 0.290 & 0.060 \\
\hline I $(1$ if $>60 K)$ & -1.248 & 0.488 & 0.011 & -1.261 & 0.494 & 0.011 & -1.231 & 0.483 & 0.012 \\
\hline M (1=Car, 0 otherwise $)$ & -1.160 & 0.329 & 0.001 & -1.175 & 0.333 & 0.001 & -1.146 & 0.325 & 0.000 \\
\hline Value of Time & $\$ 7.44$ & 0.358 & 0.000 & $\$ 8.07$ & 0.328 & 0.000 & $\$ 7.82$ & 0.293 & 0.000 \\
\hline $\operatorname{VOR}^{a}{ }^{a}(\$ / \mathrm{hr})$ & $\$ 7.11$ & 1.357 & 0.000 & & & & & & \\
\hline $\operatorname{VOR} 2^{b}(\$ / h r)$ & & & & $\$ 2.31$ & 0.757 & 0.003 & & & \\
\hline $\operatorname{VOR}^{c}(\$ / \%$ increase $)$ & & & & $\$ 0.84$ & 0.303 & 0.006 & & & \\
\hline $\mathrm{VOR}^{d}(\$ / \mathrm{hr})$ & & & & & & & $\$ 6.93$ & 2.066 & 0.001 \\
\hline Reliability Ratio & & & & & & & 0.89 & 0.265 & 0.001 \\
\hline \multicolumn{10}{|l|}{ Fit Statistics } \\
\hline Subjects & & 177 & & & 177 & & & 177 & \\
\hline Question per Subject & & 13 & & & 13 & & & 13 & \\
\hline -2logLiklihood & & 2004.8 & & & 1986.1 & & & 2023.3 & \\
\hline
\end{tabular}

${ }^{a}$ Value of reliability (per hour decrease in the average lateness).

${ }^{b}$ Value of reliability (per hour decrease in right range).

${ }^{c}$ Value of reliability (per percentage point change in lateness probability).

${ }^{\mathrm{d}}$ Value of reliability (per hour decrease in the standard deviation).

As expected, there is also an aversion to increased probabilities of lateness. For each $1 \%$ increase in the lateness probability of one route over another, all other things equal, the odds of choosing that route are $2.95 \%$ less. A $1 \%$ increase in the probability of being more than $5 \mathrm{~min}$ late is valued at $\$ 0.84$ (CI $\$ 0.24$ to $\$ 1.44)$. This implies that small changes in the percentage quickly outweigh changes in the range coefficient. For example if the probability of being more than 5 min late goes up by 0.05 , then the odds of choosing that alternative drop by about $13.9 \%$. It would require about a $9.1 \%$ increase on a right range of 20 min to effect a similar change in odds.

The last model (Model 3) uses the standard deviation as a measure of reliability. Again here we see that a higher standard deviation is a source of disutility as are higher travel time and higher cost. It is less obvious to the user what a unit reduction in standard deviation implies to their everyday trip. The value of reliability for this model is $\$ 6.93 / \mathrm{hr}$ (CI $(\$ 2.85 / \mathrm{hr}$ to $\$ 11.00 / \mathrm{hr})$. The VOT is estimated at $\$ 7.82 / \mathrm{hr}$ (CI $(\$ 7.25 / \mathrm{hr}$ to $\$ 8.40 / \mathrm{hr}$ ), which overlaps with the estimates from Models 1 and 2. The estimate of the reliability ratio for our model, which is based on the most frequent time rather than the expected time is 0.89 (CI ( 0.62 to 1.41 ). This means reliability is valued between $38 \%$ less to $41 \%$ more than travel time. Noland and Small (1998) estimated a reliability ratio of 1.27 , and Small et al. (1999) estimated a reliability ratio of 3.22. Black and Towriss (1993) in the United Kingdom found a value of 0.55 for the reliability ratio for car trips to/from work. It is likely that some of the differences can be the result of population differences between the study areas.

In all three cases, the dependent choice had the higher reliability (i.e. it had the lower standard deviation (S), the smaller right range (R) and the smaller average lateness $(\mathrm{L})$ ). The demographic variables can be understood as adjustments to the base condition (lower level of each) in the intercept term. Both gender and age are negative in all three models and have a $p$ that is slightly more than 0.05 but less than 0.1 . The signs of the estimates imply that women were more predisposed to select the reliable choice than men, all other things equal. People who are younger than 35 years of age were also more predisposed toward the reliable alternative than those older, all other things equal. These trends are both weak, however.

Regarding the income variable, individuals making more than $\$ 60,000$ annually were much less disposed to choose the reliable route as compared to their counterparts making less than $\$ 60,000$. As mentioned earlier, no difference was detected between those that made less than $\$ 30,000$ and those making between $\$ 30,000$ and $\$ 60,000$. The disposition by the higher income group is possibly the result of the flexibility that higher paying jobs have that is not shared by lower and medium-paying jobs. Last, those that used alternative modes of transport were more predisposed toward the more reliable route, as opposed to the regular car users. A majority of these individuals are bus 
users whose experience is tied to a more reliable mode and that may explain their preference.

Although each of the measures of reliability tells us something slightly different, they are not entirely independent of one another. In slightly different ways each is measuring the spread of the travel time, so it is not entirely surprising that all three measures of reliability came out significant. However, it is important to look at what each formulation implies. The first model brings together all the information of the distribution in a succinct manner. The probabilities work as weighing factors to moderate the effects of extreme travel times that are rare. Larger probabilities give importance to outcomes that are more commonly observed. The second model on the other hand looks at the range and the distribution separately. Hence, distributions that have similar lateness probabilities and range but are distributed in very different manners are not distinguished. The last option measures the overall variation using the standard deviation; however, as can be seen from the results, by using Model 3, importance is apparently given to early arrival that the more detailed Models 1 and 2 do not show. We believe the inclusion of both frequency and experienced time together makes Model 1's formulation more appealing.

Overall, these results support the idea that reliability offers new policy opportunities that may be used to improve the transportation experience of users. This is especially the case as demand is continuously increasing, without concomitant increases in capacity. The almost equal values attached to reliability as travel time suggests that by recognizing the various susceptibilities of different types of networks, transportation policy makers can derive significant benefits to users.

\section{CONCLUSION}

This research explores the tradeoffs users make when choosing routes. The study uses a computer-administered stated preference survey to estimate values of reliability using three different measures of reliability. The survey hedges against respondent error by including tutorials as well as incorporating control questions to gauge if respondents have understood the survey.

The paradigm adopted in this study considers the mode travel time as the important basis for travel time decisions rather than the more abstract mean travel time from the users' perspective. This is because decisions are often related to experience and recollections tend to lump together different but close travel times together. Three different measures of reliability are investigated. The first uses a moment-of-time approach, by calculating the expected lateness and earliness relative to the usual travel time. The second uses the right range of travel time from the median along with probabilities of lateness. The last one uses the standard deviation.

The different specifications offer insight into how each variable is traded off in decision making with travel time and monetary cost. For instance, the results indicate that reducing one minute on the average experienced lateness is valued very close to reducing travel time. Such close valuation between time and reliability begs for new strategies for deriving user benefits that are perhaps less costly than roadway expansion.

Operationally, these strategies can encompass giving better information to travelers through the use of advanced traveler information systems to policy decisions devised to manage demand. For example, the travel time experienced on freeways is very susceptible to accidents. Because freeways have limited entry and exit points, travelers can experience very large unexpected delays. On the other hand arterials are less susceptible to such breakdowns. By actively notifying travelers what to expect before entering a freeway, or providing rerouting guidance, a system administrator can reduce costs of excess delay and offer travelers better choices. Policy makers can also look to pricing strategies that can both reduce travel time and increase reliability on freeway segments. Ways can be sought to make reliability one criteria for how signals are timed and synchronized on arterials. By valuing reliability, meaningful comparisions can be made between different policy alternatives.

\section{REFERENCES}

Black, I., and Towriss, J. (1993). Demand effects of travel time reliability. London: Cranfield Institute of Technology, Centre for Logistics and Transportation.

Brownstone, D., and Small, K. A. (2005). Valuing time and reliability: Assessing the evidence from road pricing demonstrations. Transportation Research, Part A: Policy \& Practice, 39, 279-293.

de Palma, A. A., and Picard, N. (2006). Equilibria and information provision in risky networks with risk-averse drivers. Transportation Science, 40, 393-408.

Gaver, D. P. (1968). Headstart strategies for combating congestion. Transportation Science, 2, 172-181.

Jackson, W. B., and Jucker, J. V. (1982). An empirical study of travel time variability and travel choice behavior. Transportation Science, 16, 460-475.

Khattak A., Koppelman, F., and Schofer, J. (1993). Stated preferences for investigating commuters' diversion propensity. Transportation, 20, 107-127.

Khattak A., Polydoropoulou, A., and Ben-Akiva, M. (1996). Modeling revealed and stated pre-trip travel response to ATIS. Transportation Research Record, 1537, 46-54.

Louviere, J. J., Hensher, D. A., and Swait, J. D. (2000). Stated choice methods. Cambridge, England: Cambridge University Press.

Nicholson, A., Schmöcker, J., and Bell, M. (2003). Assessing transport reliability: Malvolence and user knowledge. In M. G. H. Bell and Y. Iida (Eds.), The network reliability of transport: Proceedings of the 1st International Symposium on Transportation Network Reliability. Amsterdam: Elsevier.

Noland, R. B., and Polak, J. W. (2002). Travel time variability: A review of theoretical and empirical issues. Transport Reviews, 22, 39-54.

Noland, R. B., and Small, K. A. (1998). Simulating travel reliability. Regional Science \& Urban Economics, 28, 535-564. 
Schmöcker, J., and Lo, H. K. (2009). Editorial: Special issue on improving network reliability through ITS technologies. Journal of Intelligent Transportation Systems, 13, 1.

Small, K. A. (1982). The scheduling of consumer activities: Work trips. American Economic Review, 72, 467-479.

Small, K. A., Noland, R. B., Chu, X., and Lewis, D. (1999). Valuation of travel-time savings and predictability in congested conditions for highway user-cost estimation. Washington, DC: National Research Council, Transportation Research Board.
Yang, H., Lo, K. K., and Tang, W. (2000). Travel time versus capacity reliability of a road network. In M. G. H. Bell and C. Cassir (Eds.), Reliability in transport networks (pp. 119-138). Hertfordshire, UK: Research Studies Press.

Zhang, L. (2006). Search, information, learning and knowledge in travel decision-making: A positive approach for travel behavior and demand analysis. Ph.D. Dissertation, University of Minnesota, Minneapolis, Department of Civil Engineering. 